\title{
FURTHER OBSERVATIONS ON THE HEMODYNAMIC EFFECT OF PLASMA VOLUME EXPANSION BY DEXTRAN ${ }^{1}$
}

\author{
BY J. W. FLEMING AND W. L. BLOOM \\ (From the Piedmont Hospital, Atlanta, Ga., and the Medical Research Laboratory, Veterans \\ Administration Hospital, Chamblee, Ga.)
}

(Submitted September 6, 1955; accepted April 11, 1957)

An earlier study (1) indicated that the administration of $500 \mathrm{ml}$. of 6 per cent dextran to five patients produced hemodilution and increased the cardiac output. There was insufficient evidence in this study to correlate the increase in cardiac output with any phase of the hemodynamic change resulting from plasma volume expansion. In order to extend the previous observations, right auricular, pulmonary arterial, pulmonary wedge pressure, cardiac output, and plasma volume were measured in 16 patients with varying degrees of hypervolemia following dextran injection. Data to be presented indicate that factors other than elevated right auricular, pulmonary arterial or pulmonary wedge pressures were operative in altering the response of the cardiac output of normal individuals to plasma volume expansion by a diluent such as 6 per cent dextran and by 12 per cent salt-free dextran. Increase in cardiac output was generally observed following hypervolemia.

\section{MATERIALS AND METHODS}

The patients were studied in the fasting state. All except one (No. 15) were male, and their ages ranged from 22 to 44 years. All of the 16 patients were afebrile and ambulatory. Diagnoses are listed in Table I. The partially hydrolyzed 6 per cent dextran solution had a viscosity ranging from 2.7 to 3.3 centistokes at $25^{\circ} \mathrm{C}$. and was made up in 0.85 per cent saline. ${ }^{2}$ The 12 per cent dextran solution was salt-free and had a viscosity of 8.8 centistokes at $25^{\circ} \mathrm{C}$.

Intravenous catheterizations were performed with a 6-F or 8-F intracardiac catheter. The systemic arterial blood samples and pressure records were obtained from an indwelling, femoral arterial needle. An electromanometer (Sanborn) was used for all pressure tracings. Arbitrary zero reference was $5 \mathrm{~cm}$. below the level of the sternal angle of Louis. Mean pressures were ob-

1 Dextran and intrinsic viscosity measurements were kindly supplied by Dr. Homer Stavely, Commercial Solvents Corporation, Terre Haute, Indiana.

2 Reviewed by the Veterans Administration and published with the approval of the Chief Medical Director. The statements and conclusions published by the authors are the result of their own study and do not necessarily reflect the opinion or policy of the Veterans Administration. tained by electrical integration of the pulse contours. Pulmonary wedge pressures were obtained as described by Hellems, Haynes, and Dexter (2). Peripheral venous pressure and some atrial pressures were measured with a saline manometer, using the same zero reference point as above.

Cardiac outputs were derived by the method of Kinsman, Moore, and Hamilton $(3,4)$ using Evans Blue Dye (T-1824). As shown in Table $I$, three patients (Cases 10,11, and 12) showed variations of less than 5 per cent in consecutive dye output determinations made prior to alterations induced by plasma volume expansion. Mean pulmonary circulation time was obtained by plotting the semi-logarithmic dye curves arithmetically and determining planimetrically the mean division of the area beneath the curve. Pulmonary vascular resistance was calculated according to the formula mentioned by Dexter, Dow, Haynes, Whittenberger, Ferris, Goodale, and Hellems (5).

Blood volume was determined according to the method of Gibson and Evans (6) ; multiple specimens were obtained starting 10 minutes following the injection of Evans Blue Dye.

The experiments were done as follows: The patients were given mild sedation ( 0.1 to 0.2 gram of sodium phenobarbital intramuscularly) prior to catheterization. The catheter tip was passed either into the superior vena cava (Case 6 ), the right atrium, the right ventricle, or the pulmonary artery, and the indwelling femoral arterial needle was inserted. An initial dye injection into the heart was made, and several pressure determinations were made. One thousand or $1,500 \mathrm{ml}$. of 6 per cent dextran or the 12 per cent dextran were given intravenously at the rate of $25 \mathrm{ml}$. per minute. Pressure readings were recorded during the control period, midway in the administration of the dextran, immediately after its completion, and at frequent intervals thereafter. Second dye injections were done within 10 minutes after dextran administration in most patients. Other dye injections were made after 15 minutes to 2 hours. Subsequent pressure and cardiac output measurements were performed at the times recorded in Table I. Pressure readings were obtained immediately after the cardiac output.

"Plasma volume expansion" is used in the text of this paper to indicate the degree of hemodilution resulting from dextran injection, and the "initial plasma volume" is based on the apparent volume of distribution of T-1824.

\section{RESULTS}

Pertinent data are presented in Table I. Cardiac output increased in all but 3 of the 16 pa- 
TABLE I

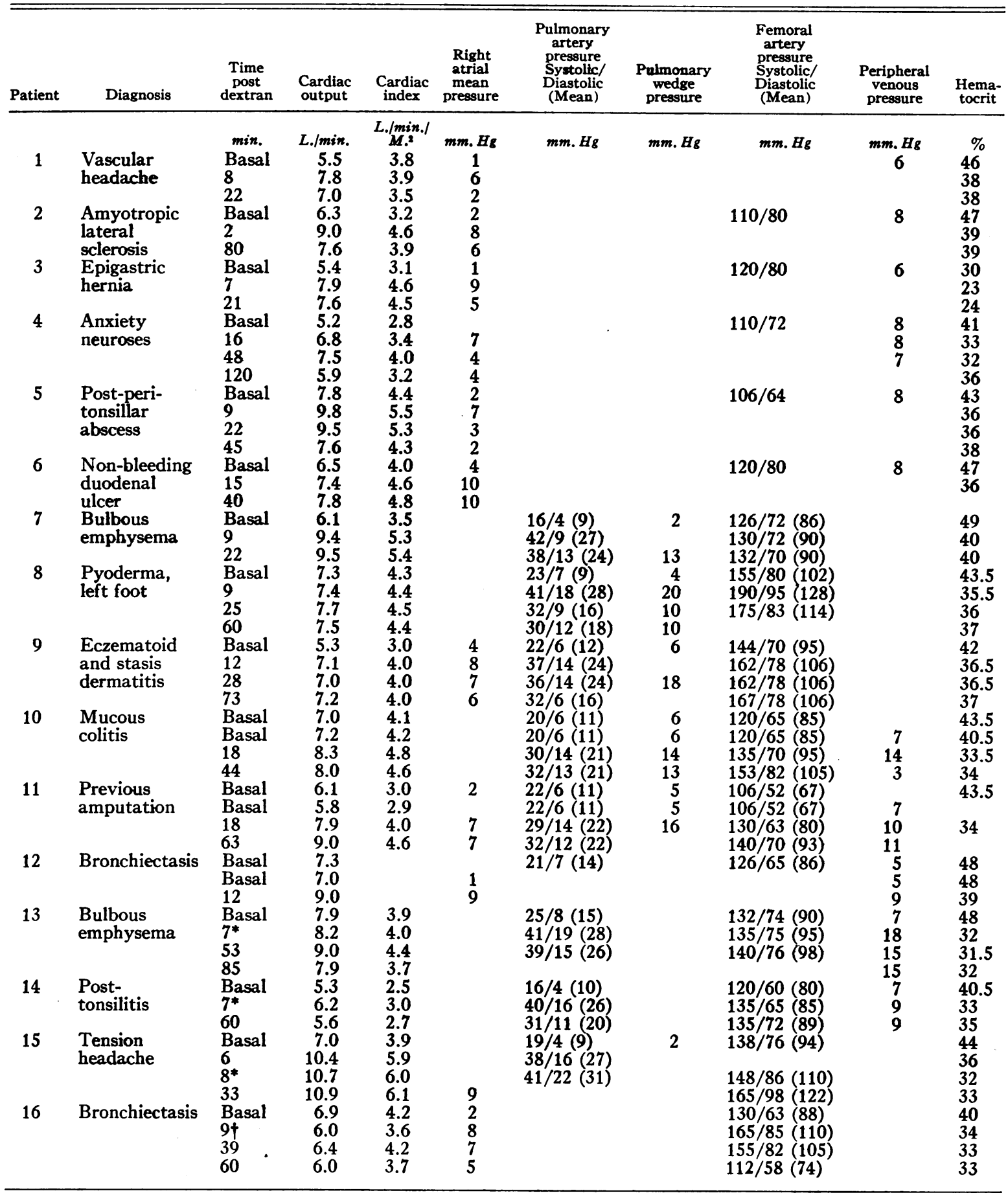

* After $1,500 \mathrm{ml} .6$ per cent dextran.

† After $300 \mathrm{ml} .12$ per cent salt-free dextran.

tients (Cases 8,13, and 16, Table I). Two of these patients received $1,000 \mathrm{ml}$ of 6 per cent dextran and the other patient received $300 \mathrm{ml}$. of 12 per cent dextran. Three other patients (Cases
6,10 , and 14) had increases of 15 per cent when cardiac output determinations were done within 20 minutes following end of infusion. In the remaining 10 patients, cardiac increases in output 
ranged from 26 per cent to 53 per cent with an average increase of 44 per cent. A representative response (Case 9) is depicted in Figure 2. Previous results (1) indicated an increase of cardiac output in five of five patients; thus the total of the two reports indicates increases in cardiac output in 18 of 21 instances of plasma volume expansion. Data of the present investigation showed no correlation between the elevations of right auricular or pulmonary arterial pressure and the increase in cardiac output. The highest elevation in peripheral venous pressure was associated with no change in cardiac output (Case 13), whereas the smallest changes in peripheral venous pressures were accompanied by a 16 per cent and 30 per cent increase in cardiac output in two other patients (Cases 4 and 14). Of the three patients who received $1,500 \mathrm{ml}$. of 6 per cent dextran, only one (Case 15) showed a marked increase in cardiac output. This observation could be applied to all of the studies in that there was no correlation of the increase in cardiac output and the extent of plasma volume expansion.

Pulmonary arterial pressure increased in all eight patients studied (mean pressure increase, $11.5 \pm 5.2)$. Both systolic and diastolic pulmonary arterial pressures increased in all instances, but the systolic pressure increased more than the diastolic. Right atrial pressure increased in all 10 patients studied, and the pressure remained elevated during the course of observation in 8 of 10 patients. The right atrial pressure was highest immediately following infusion and subsequently decreased toward pre-infusion levels. The right atrial pressure decreased more rapidly than did the pulmonary arterial pressure.

No significant association was found in the linear regression of the change from control of the cardiac output (liter per minute) (Y) on the mean right atrial pressure $(\mathrm{mm} . \mathrm{Hg})(\mathrm{X})$, (Slope $b=0.010 \pm 0.146, p=>0.1$ ). Similarly, when all cardiac output $(\mathrm{Y})$ values are plotted against all right atrial pressures (X), no significant linear regression was observed (Slope $b=0.55 \pm 0.092$, $\mathrm{p}=0.1)$.

The pulmonary wedge pressure increased between 7 and $15 \mathrm{~mm} . \mathrm{Hg}$ in five patients. Following dextran infusions, the gradient from pulmonary artery to pulmonary "capillary" showed no change in two patients and an increase of 2 to 4 $\mathrm{mm}$. $\mathrm{Hg}$ in three patients. Pulmonary vascular resistance measured in five patients was found not to change significantly. Peripheral venous pressures were observed in eight patients. Immediately following infusion, this pressure increase (not listed in Table) exceeded $4.4 \mathrm{~mm}$. $\mathrm{Hg}$ in all but one patient (Case 14) in which the pressure increased $2.5 \mathrm{~mm}$. $\mathrm{Hg}$. Three of four patients showed persistent moderate to marked elevations of peripheral venous pressure for over an hour. In the other patient, the venous pressure remained elevated for 25 minutes, then rapidly fell to below the initial pressure.

Femoral arterial mean pressure increased an average of $17 \mathrm{~mm}$. $\mathrm{Hg} \pm 3, \mathrm{p}=0.001$ in all patients studied. The pulse pressure increased 8.3 mm. $\pm 3.3, p=>0.02$. Mean arterial pressures remained elevated one hour after infusion in all patients studied; in fact, arterial pressures at the end of one hour were often higher than immediate post-infusion levels. Femoral arterial pressure increases were, on the whole, no larger following $1,500 \mathrm{ml}$. than following 500 or $1,000 \mathrm{ml}$. Pulse rate was unchanged in eight patients following dextran infusion and six showed increases of 8 to 30 beats per minute. Changes in hematocrit following dextran infusions show that plasma volume expansion occurred in all patients and was maintained during the observation period. Other studies (7) have shown that the hematocrit gradually returns to normal over a period of five days following infusion of 6 per cent dextran.

\section{DISCUSSION}

In a previous study the administration of $500 \mathrm{ml}$. of 6 per cent dextran produced moderate elevations of pulmonary arterial pressures, while peripheral venous and systemic arterial pressure changes were small (1). In contrast, right atrial, pulmonary arterial and femoral arterial pressures were all elevated in the present study following the infusion of 1,000 and $1,500 \mathrm{ml}$. of dextran. The magnitude of the pulmonary pressure change in the presented data is greater than that in the peripheral veins and right auricle. Plasma protein infusions were previously reported to produce only transient increase in peripheral venous and arterial pressures (8), and the absence of pressure change was ascribed to generalized vasodilation which accommodated the expanded volume; however, these studies with dextran indi- 


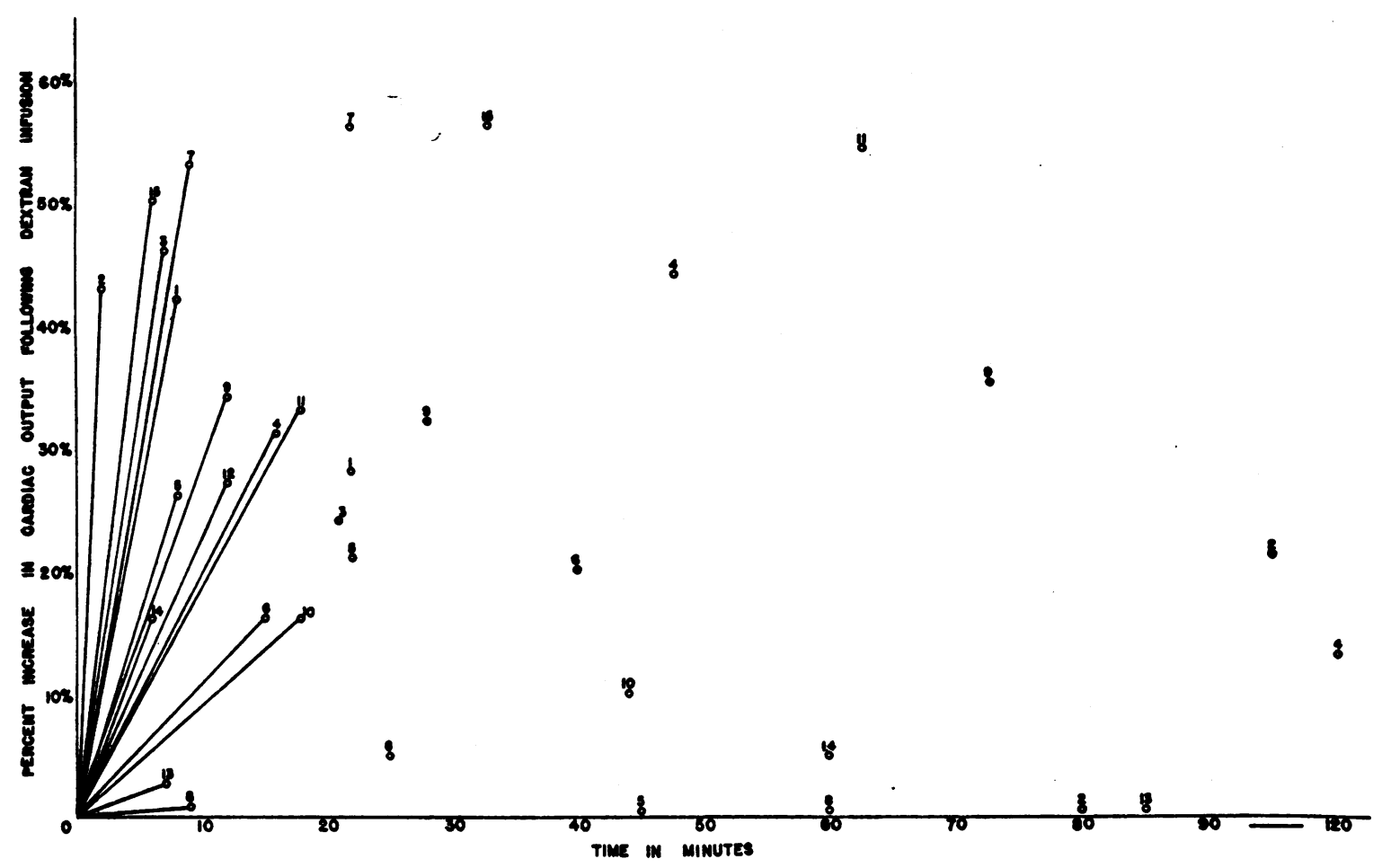

Fig. 1. Per Cent Change in Cardiac Output Following Infusion of 1,000 and 1,500 m. of 6 Per Cent Dextran

cate that the adjustment of vascular space to vascular volume is not maintained at control levels.'

The data of Doyle, Wilson, Estes and Warren (9) and the findings of this study showed that comparable changes occur in pulmonary arterial and pulmonary wedge pressure. These data suggest that the left atrial, and possibly the left ventricular diastolic, pressure is elevated following plasma volume expansion. Although these changes might be suggestive of left ventricular failure, it would seem premature to speculate on this point before the performance of the left ventricle under increased work load is measured. In this regard, Morrison and Bloom (10) observed pulmonary hemorrhage rather than pulmonary edema as a result of maximal plasma volume expansion in dogs. Apparently, increased pulmonary vascular pressures as well as extreme hemodilution, anemia, and altered hemostasis produced this result.

The observation that cardiac output increased following hemodilution and hypervolemia confirmed the results of McMichael and SharpeySchafer (11). However, Warren, Brannon,
Weens and Stead (12) indicated only an inconstant increase in cardiac output following plasma volume expansion with human albumin. It is possible that the conflict in the results of these experiments might be related to differences in materials used for plasma volume expansion, varying rates of administration of the expander, the degree of anemia from hemodilution (13), changes in peripheral resistance (14), as well as other unconsidered variables.

McMichael and Sharpey-Schafer (11) found increase in cardiac output and increase in right atrial pressure following rapid intravenous infusion of saline in six patients. In the present study, increase in right atrial pressure was frequently observed following plasma volume expansion with dextran; however, there was no significant association between increase in right atrial pressure and increase in cardiac output. These two experiments have demonstrated increase in right atrial pressure and increase in cardiac output following plasma volume expansion, but there was no evidence to show that the increase in cardiac output was related to atrial pressure changes. Despite 
increased pressure in peripheral veins, right atrium, pulmonary artery, and pulmonary "capillary," as well as plasma volume expansion, the heart only shows a small increase in output in relation to its known capacity. Plasma volume expansion and the resulting hemodynamic changes have not been found to produce maximal changes in cardiac output.

\section{CONCLUSIONS}

Following intravenous administration of 1,000 to $1,500 \mathrm{ml}$. of 6 per cent dextran to normal individuals, there is prolonged plasma volume expansion. This increased plasma volume alters normal pressure-volume relationships in both the pulmonary and systemic vascular circuits, causing relatively greater increases in pressure in the pulmonary system. In some patients, accommodation to this plasma volume expansion might occur by generalized capillary and venous dilation, allowing the systemic venous and right atrial pressure to return toward normal levels. Cardiac output is usually increased, but this increase is not consistently associated with any measured pressure change in the venous or pulmonary system or the degree of plasma volume expansion. In contrast, a few patients with an expanded plasma volume may fail to increase cardiac output in spite of high right atrial and pulmonary arterial pressures.

\section{SUMMARY}

1. One thousand to $1,500 \mathrm{ml}$. of 6 per cent dextran in physiologic saline solutions were given in-

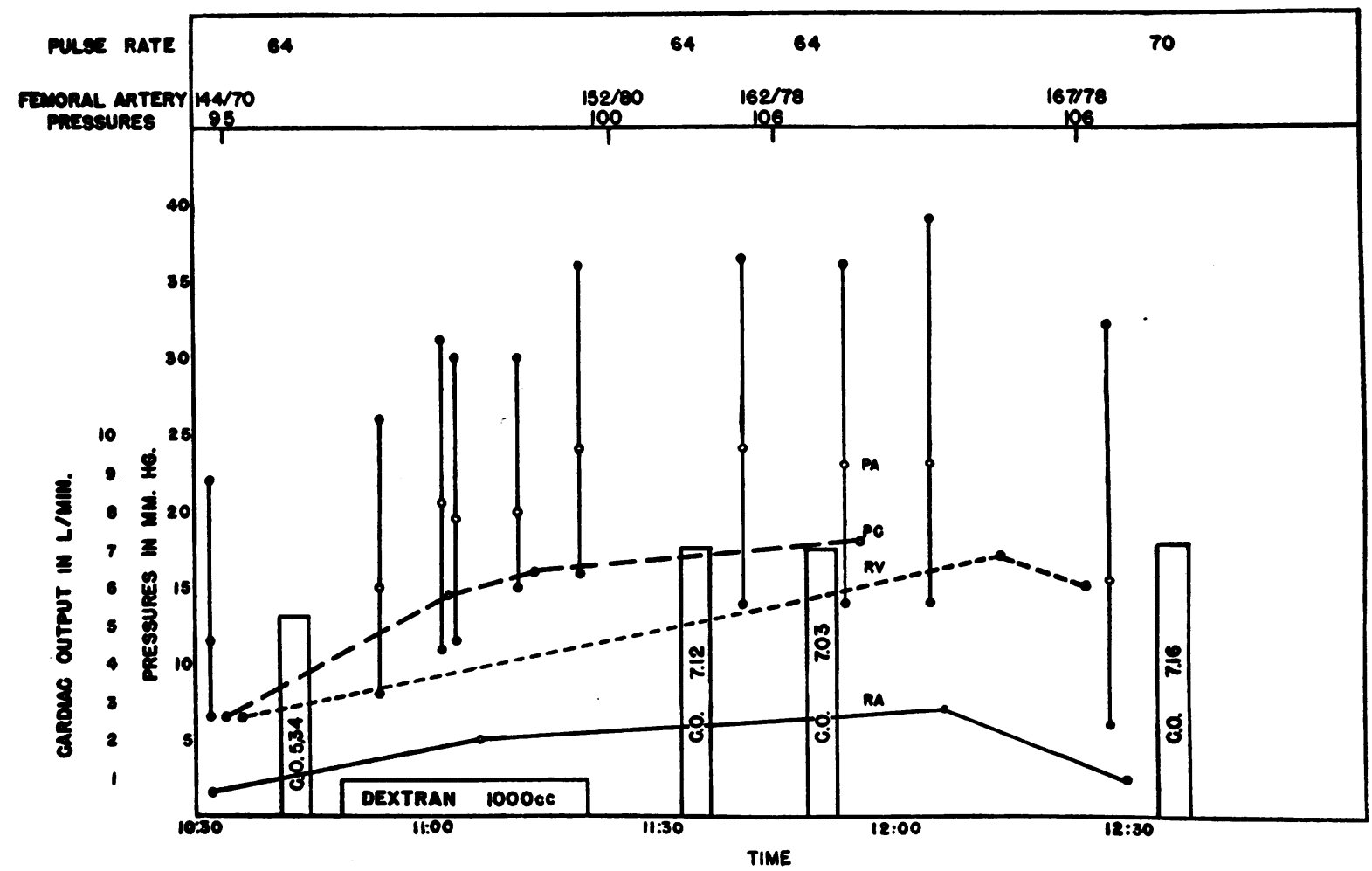

Fig. 2. Hemodynamic Change Following the Intravenous Administration of 1,000 ml. of 6 Per Cent Dextran in Case 9

C. O. = Cardiac output

P. A. = Pulmonary arterial mean pressure

P. C. = Pulmonary "capillary" mean pressure

R. A. = Right atrial mean pressure

R. V. = Right ventricular pressure

Pulmonary arterial systolic and diastolic pressures are represented by the solid dots connected to the mean pulmonary arterial pressure representation. 
travenously at the rate of $25 \mathrm{ml}$. per minute to 16 subjects, most of whom were convalescent.

2. Cardiac output increased 25 to 53 per cent in 10 patients, 15 per cent in three patients, and did not increase in three individuals.

3. Right atrial and pulmonary arterial pressure elevations increased markedly and were usually prolonged in all patients following dextran injections. The data indicate that increases in cardiac output cannot be related to increases in right atrial, pulmonary arterial or pulmonary wedge pressures.

\section{REFERENCES}

1. Witham, A. C., Fleming, J. W., and Bloom, W. L., The effect of the intravenous administration of dextran on cardiac output and other circulatory dynamics. J. Clin. Invest., 1951, 30, 897.

2. Hellems, H. K., Haynes, F. W., and Dexter, L., Pulmonary 'capillary' pressure in man. J. Applied Physiol., 1949, 2, 24.

3. Kinsman, J. M., Moore, J. W., and Hamilton, W. F., Studies on the circulation. I. Injection method: Physical and mathematical considerations. Am. j. Physiol., 1929, 89, 322.

4. Hamilton, W. F., Moore, J. W., Kinsman, J. M., and Spurling, R. G., Studies on the circulation. IV. Further analysis of the injection method, and of changes in hemodynamics under physiological and pathological conditions. Am. J. Physiol., 1932, 99, 534.

5. Dexter, L., Dow, J. W., Haynes, F. W., Whittenberger, J. L., Ferris, B. G., Goodale, W. T., and Hellems, H. K., Studies of the pulmonary circulation in man at rest. Normal variations and the interrelations between increased pulmonary blood flow, elevated pulmonary arterial pressure, and high pulmonary "capillary" pressures. J. Clin. Invest., 1950, 29, 602.

6. Gibson, J. G., 2nd, and Evans, W. A., Jr., Clinical studies of the blood volume. I. Clinical application of a method employing the Azo dye "Evans Blue" and the spectrophotometer. J. Clin. Invest., 1937, 16, 301.

7. Bloom, W. L., Present status of plasma volume expanders in the treatment of shock: clinical laboratory studies. Arch. Surg., 1951, 63, 739.

8. Wilson, J. R., Jr., and Harrison, C. R., Cardiovascular, renal, and general effects of large, rapid plasma infusions in convalescent men. J. Clin. Invest., 1950, 29, 251.

9. Doyle, J. T., Wilson, J. S., Estes, E. H., and Warren, J. V., The effect of intravenous infusions of physiologic saline solution on the pulmonary arterial and pulmonary capillary pressure in man. $\mathrm{J}$. Clin. Invest., 1951, 30, 345.

10. Morrison, J. L., and Bloom, W. L., The effect of continuous infusion of hydrolyzed dextran on the cardiovascular system of the dog. J. Pharmacol. \& Exper. Therap., 1951, 103, 355.

11. McMichael, J., and Sharpey-Schafer, E. P., Cardiac output in man by a direct Fick method. Effects of posture, venous pressure change, atropine, and adrenaline. Brit. Heart J., 1944, 6, 33.

12. Warren, J. V., Brannon, E. S., Weens, H. W., and Stead, E. A., Jr., Effect of increasing the blood volume and right atrial pressure on the circulation of normal subjects by intravenous infusions. Am. J. Med., 1948, 4, 193.

13. Gowdey, C. W., and Young, I. E., Cardiorenal effects of large infusions of dextran in dogs. Canad. J. Biochem. \& Physiol., 1954, 32, 559.

14. Hamilton, W. F., Role of the Starling concept in regulation of the normal circulation. Physiol. Rev., $1955,35,161$. 